Research Article

\title{
Family Factors Associated with Consumption of Spirits: A Comparative Gender-Based Study of Ugandan Students in Public Secondary Schools
}

\author{
Aloysius Rukundo, ${ }^{1}$ David Santson Ayebare ${ }^{(D)},{ }^{2}$ Grace Kibanja, ${ }^{3}$ and Karl Steffens ${ }^{4}$ \\ ${ }^{1}$ Department of Educational Foundations and Psychology, Mbarara University of Science and Technology, Mbarara, Uganda \\ ${ }^{2}$ Interdisciplinary Research \& Development Center Limited, Mbarara, Uganda \\ ${ }^{3}$ School of Psychology, Department: Mental Health and Community Psychology, Makerere University, Kampala, Uganda \\ ${ }^{4}$ Department of Education, University of Cologne, Cologne, Germany
}

Correspondence should be addressed to David Santson Ayebare; ayebaredavid@gmail.com

Received 12 August 2019; Revised 7 November 2019; Accepted 18 November 2019; Published 10 January 2020

Academic Editor: Bernhard Schmidt-Hertha

Copyright (c) 2020 Aloysius Rukundo et al. This is an open access article distributed under the Creative Commons Attribution License, which permits unrestricted use, distribution, and reproduction in any medium, provided the original work is properly cited.

\begin{abstract}
This study aims at investigating family factors associated with consumption of spirits across gender of students in public secondary schools in Uganda. A cross-sectional survey using self-administered questionnaires was used to collect data on consumption of sprits in the past 12 months prior to the study. Of the 1,591 students recruited, the overall prevalence of consumption of spirits was found to be $17.3 \%(n=275)$ with higher consumption of spirits among males $(20.3 \%)$. Results indicate that unemployed heads of families $(\mathrm{aOR}=2.5,95 \% \mathrm{CI}: 1.30-4.76, p<0.01)$, fairly religious $(\mathrm{aOR}=2.7,95 \% \mathrm{CI}: 1.08-6.49, p<0.05)$, and not religious families $(\mathrm{aOR}=2.9,95 \% \mathrm{CI}: 1.17-7.11, p<0.05)$ were factors associated with consumption of spirits. Early prevention of consumption of spirits could be focused on male students, fathers' occupation, and family religiosity. In addition, school administrators and authorities could consider these factors during routine school inspections to guard discipline among students in Uganda.
\end{abstract}

\section{Introduction}

There is increasing trend of consumption of alcohol among the youth worldwide. However, few studies have identified family factors associated with gender differences in consumption of spirits among students. Nonetheless, one of the foremost social frameworks impacting adolescent decisions to consume alcohol is the family $[1,2]$. The subject of family and consumption of spirits is a relatively rare subject in the Ugandan context. Conversely, most studies regarding the subject have mainly focused on adults, yet development and perpetuation of unhealthy lifestyle patterns is largely during adolescence-secondary school age [3].

That notwithstanding, the fundamental idea is that alcohol consumption among the youth in Uganda is central to the economy and social life of the family and community [4].
Moreover, the patterns of alcohol consumption among the youths in Uganda show signs of family influence [5]. The family, as part of the social apparatus, defines alcohol consumption among Uganda's youthful populations [6-8]. Despite these sources underpinning family dynamics as controlling youth drinking in Uganda, and to the best of our knowledge, no single study has set to investigate family influences on alcohol consumption among the youth. The status quo makes intervention plans to control drinking in schools hard to estimate. The aim of this study, therefore, was to build on the paucity of the literature and underpin gender differences in the association between select family influences and consumption of spirits among students in Ugandan public schools.

Family location has previously been reported as a part of the social environments that influence alcohol consumption 
among adolescents. It was found that compared with those living in major cities, adolescents from rural areas were at higher odds of drinking for the past 12 months [9]. Gale and others further established that parents of adolescents from rural areas had higher odds of weekly drinking and drinking at home. Similarly, rural adolescents with low household income were more likely than urban adolescents with similar income to have consumed alcohol [10]. However, there were no rural-urban gender differences in drinking among adolescents [10].

Nevertheless, an array of studies elsewhere point to gender differences in alcohol consumption among the youth. As a result, Gruenewald et al. [11] suggest inclusion of gender in the future research to investigate about the specific types of alcohol consumed among the youth. In the same regard, Osman et al. [12] reported that being male was significantly associated with alcohol consumption. Reports from civil society organizations and other sporadic literature reveal that male and female youth in Uganda prefer especially locally made spirits. Moreover, UYDEL [4] reports that students, especially day scholars, both male and female, stealthily smuggled huge amounts of spirits into schools for sale. In resonance with other sources, the Uganda Alcohol Policy Alliance [13] report agitates that spirits in sachets are very popular, among male and female youth in schools. Similar studies in Uganda show that gender is a phenomenon of concern with respect to alcohol consumption among the youth. In fact, Swahn et al. [14] observed significant associations of gender with alcohol consumption. To that effect, boys were more likely than girls to report current alcohol use, drunkenness, or problem drinking.

Studies elsewhere estimate alcohol consumption among secondary school adolescents to be rooted in students' living arrangements. For instance, in their study to assess correlates of alcohol use among boarding secondary schools adolescents, Osaman et al. [12] found that living with guardians or alone was significantly associated with alcohol consumption. Accordingly, students who stayed with friends or alone had higher odds of using alcohol than students who stayed with their family.

To another extent, family influences regarding alcohol consumption among adolescents are inclusive of other factors, such as family religious values. For instance, it has been opined that family religiosity and growing up with religious parents significantly predicted low alcohol consumption among youth [8]. It is widely believed that when parents or guardians hold strong religious values, their children are less likely to consume alcohol [15].

Further, parental occupation and socioeconomic status are consistently reported as being related to alcohol consumption among the youth. For instance, adolescents from economically disadvantaged families were more likely to consume (low-price) alcohol than their counterparts from affluent families [16]. Parents' occupation dictates how much time parents will dedicate to their families and hence the quality of relationship between parents and adolescents [17]. Moreover, family socioeconomic status is likely to predict students' lifestyles (e.g., how much money they have to spend on luxuries including alcohol). Parental occupation and income further determine family environment-where the home will be located and who the children associate with. Miller and Cook [18] found that family environment influences alcohol consumption among adolescents. To the contrary, Gough et al. [19] observed that having positive family relationships did not influence consumption of alcohol. The objective of this study was to investigate the family factors associated with consumption of spirits across the gender of students in public schools in Uganda.

\section{Methods}

The study considered a cross-sectional design and quantitative methods in data collection, analysis, and interpretation. The study took place from 2013 to 2014. Schools were purposively sampled to consider public schools only. The schools were all located in urban settings. Students were sampled randomly to give every member an equal chance to participate. The sample (computed using Leslie's [20] formula) was 323 . This sample was then upscaled to increase the statistical power of the findings. The final sample of the study was 1,982 students recruited from the 13 secondary schools. The names of schools are kept anonymous. Of these, 1,819 students returned the questionnaires. 168 (9.6\%) students were excluded from the analyses, as they had missing data on most variables included in this paper. The final analyses included 1,591 participants, based of disproportionate numbers of males (946) and females (645). A self-administered questionnaire in English was used, as English is the medium of instruction among Ugandan schools.

The instrument contained items to capture students' familial factors including gender, parents' occupation, and mode of residence and family religiosity, family economic status, and place of residence. Consumption of spirits was examined by asking students to indicate, for the previous 12 months, the extent to which they took alcohol in form of spirits (Uganda waragi, Kasese/nguli, among others). Responses to the study item were initially based on a five-point likert-scale. The responses were however dummied to denote "yes" and "no" for profiling consumers and nonconsumers. Hence, consumers are described as those where their response was dummied "yes" and nonconsumers as those where the response was turned "no." Mode of residence was captured by asking the students whether they stayed with their biological parents or guardians/alone. During coding, "yes" was taken to mean staying with biological parents while "no" was taken to mean staying with either guardians or alone. Parents' occupation was initially dichotomized to mean father's occupation and mother's occupation. Students' responses regarding parental occupation were copious. They were blended to mean three categories: (1) professional occupations, (2) nonprofessional occupations, and (3) unclassified for smooth interpretation. Family religiosity was captured by asking the students to choose their family as "very religious," "somewhat religious," and "not religious." In measuring home location, students were tasked to indicate whether their homes were located in urban/town or rural locales. Perceived family economic status was captured by asking the students to state whether 
they regarded themselves as coming from very rich family, somewhat rich family, and poor family. All responses in the study tool were anonymous, as students were not requested to include identifying information such as names on the questionnaires.

Data were managed and analysed using STATA 15.0. Descriptive statistics (frequencies), chi-squares, and logistic regression models constituted the major statistical tests.

\section{Results and Discussion}

This study considered gender differences in the association between select family influences and consumption of sprits among students in Ugandan public schools. As recorded in Table 1, there were significant differences in age $(p<0.001)$, location of family residence $(p<0.001)$, fathers' occupation $(p<0.01)$, and perceived family SES $(p<0.01)$ across gender of students.

Results of logistic regressions are recorded in Table 2. After adjusting to control for confounding, we found that family religiosity and fathers' occupation remained significant predictors of consumption of spirits among males. In multivariate regressions and after adjusting for students' age and other factors, males belonging to "not religious families" were 2.7 times more likely than their counterparts from very religious families to consume spirits. Further in multivariate models, male students whose fathers belonged to the unemployed category had higher odds of consuming spirits than those from professional jobs $(\mathrm{AOR}=2.5 ; 95 \% \mathrm{CI}$ : $1.22-4.36, p<0.01)$. However, we did not estimate multivariate models for female consumers of spirits, since none of their factors were significant during bivariable analyses.

The findings that more males than females consumed spirits across the family variables resonate with previous studies regarding drinking among adolescents. It was earlier reported that males were more likely than females to consume alcohol [4]. Similarly, Swahn et al. [14] found in their Uganda-based study that boys were more likely than girls to report current alcohol use, drunkenness, or problem drinking. The present study results mirror remarkably comparable results that reported drinking practices among Ugandan adults. It was previously found that among the Ugandan adults, males were more likely to be medium-tohigh alcohol consumers [21]. Alcohol consumption behaviors among Ugandan adolescents therefore seem to follow a similar pattern as that of adults. Moreover, the observation that male students consumed spirits more than the females echo longstanding traditional view that drinking is more tolerated among males than females. Moreover, it has been opined that of nonpathological drinking behavior, sex is the single most predictor with males consuming alcohol more frequently than female counterparts [22, 23]. It is noteworthy that the present findings that male consumers were more than female consumers agree with many other studies elsewhere (e.g., [24, 25]. Similar studies show almost consistent results regarding gender and alcohol consumption. In their study to assess substance use and risky sexual behaviors among university students, Derese et al. [26] found significant gender differences in lifetime alcohol
TABle 1: Frequency distribution of sociodemographic and family factors of adolescents in public secondary schools in Uganda $(N=1.591)$.

\begin{tabular}{|c|c|c|c|c|}
\hline Characteristics & Males & Females & $N$ & $p$ \\
\hline $\begin{array}{l}\text { Age (years) } \\
12-14 \text { years } \\
15-17 \text { years } \\
18 \text { years }^{+}\end{array}$ & $\begin{array}{l}44(50.6) \\
414(50.7) \\
488(70.9) \\
\end{array}$ & $\begin{array}{c}43(49.4) \\
402(49.3) \\
200(29.1) \\
\end{array}$ & $\begin{array}{c}87 \\
816 \\
688 \\
\end{array}$ & $0.001^{* * *}$ \\
\hline $\begin{array}{l}\text { Home location } \\
\text { Rural } \\
\text { Urban } \\
\end{array}$ & $\begin{array}{l}411(65.6) \\
534(55.5) \\
\end{array}$ & $\begin{array}{l}216(34.4) \\
429(44.6) \\
\end{array}$ & $\begin{array}{l}627 \\
963 \\
\end{array}$ & $0.001^{* * *}$ \\
\hline $\begin{array}{l}\text { Live with parents } \\
\text { No } \\
\text { Yes }\end{array}$ & $\begin{array}{l}274(56.9) \\
672(60.6) \\
\end{array}$ & $\begin{array}{l}208(43.1) \\
437(39.4) \\
\end{array}$ & $\begin{array}{c}482 \\
1.109 \\
\end{array}$ & 0.162 \\
\hline $\begin{array}{l}\text { Family religiosity } \\
\text { Very religious } \\
\text { Somewhat religious } \\
\text { Not religious } \\
\text { Others }\end{array}$ & $\begin{array}{l}581(59.1) \\
342(60.6) \\
22(53.7) \\
29(74.4)\end{array}$ & $\begin{array}{c}402(40.9) \\
222(39.4) \\
19(40.5) \\
10(25.6) \\
\end{array}$ & $\begin{array}{c}983 \\
564 \\
41 \\
39 \\
\end{array}$ & 0.623 \\
\hline $\begin{array}{l}\text { Father/guardian's occu } \\
\text { Professional } \\
\text { Nonprofessional } \\
\text { Unclassified }\end{array}$ & $\begin{array}{l}\text { pation } \\
47(57.3) \\
387(55.1) \\
512(63.5) \\
\end{array}$ & $\begin{array}{l}35(42.7) \\
316(44.9) \\
294(36.5) \\
\end{array}$ & $\begin{array}{l}82 \\
703 \\
806 \\
\end{array}$ & $0.003^{* *}$ \\
\hline $\begin{array}{l}\text { Mothers' occupation } \\
\text { Professional } \\
\text { Nonprofessional } \\
\text { Unclassified }\end{array}$ & $\begin{array}{l}175(56.8) \\
570(59.4) \\
201(62.2) \\
\end{array}$ & $\begin{array}{l}133(43.2) \\
390(40.6) \\
122(37.8) \\
\end{array}$ & $\begin{array}{l}308 \\
960 \\
323 \\
\end{array}$ & 0.382 \\
\hline $\begin{array}{l}\text { Perceived parents' SES } \\
\text { Very rich } \\
\text { Somewhat rich } \\
\text { Poor }\end{array}$ & $\begin{array}{l}51(54.8) \\
530(56.6) \\
354(65.4)\end{array}$ & $\begin{array}{l}42(45.2) \\
407(43.4) \\
187(34.6)\end{array}$ & $\begin{array}{c}93 \\
937 \\
541\end{array}$ & $0.002^{* *}$ \\
\hline
\end{tabular}

consumption. In the same study, boys were three times more likely than girls to use alcohol in bivariate models. The odds ratios were increased to five when other variables were controlled for in multivariate regressions.

In other results, it was found that male consumers of spirits who did not stay with their biological parents were slightly more than females. This scenario corresponds with traditional societal values that make parents exert more control on girls than on boys. This study however did not find significant logistic results regarding consumption of spirits and living arrangements. The results are surprising, as previous studies elsewhere reported to the contrary. For instance, Lorant et al. [27] found significant associations between students' living arrangements and number of drinks and frequency of abusive drinking. In the same study, students living in dormitories had higher odds of number of drinks and frequency of drinking, compared with students who lived with parents. Moreover, Osman et al. (2016) found a significant association between accommodation status and students' alcohol consumption in bivariate but not in multivariate regressions. The inconsistencies in the extant literature and present study could have arisen as a matter of relative differences in levels of students. Whereas our study considers high school students who are still physically and consciously restricted both at home and at school, most of the previous studies dealt with college students who had relative freedoms to adventure into alcohol consumption. 
TABLE 2: Logistic regressions showing the association between Family factors and consumption of spirits among students.

\begin{tabular}{|c|c|c|c|c|c|c|c|}
\hline & \multicolumn{2}{|c|}{$\begin{array}{l}\text { Consumption of spirits } \\
\text { among males }\end{array}$} & \multirow[t]{2}{*}{ UOR (95\% CI) } & \multirow[t]{2}{*}{$\operatorname{AOR}(95 \% \mathrm{CI})$} & \multicolumn{2}{|c|}{$\begin{array}{c}\text { Consumption of } \\
\text { spirits among females }\end{array}$} & \multirow[t]{2}{*}{ UOR $(95 \% \mathrm{CI})$} \\
\hline & Yes & No & & & Yes & No & \\
\hline \multicolumn{8}{|l|}{$\begin{array}{l}\text { Age }(\text { mean }=17.3, S D= \\
1.9, \text { range }=12-25)\end{array}$} \\
\hline $12-14$ years & $5(11.4)$ & $39(88.6)$ & 1.0 & 1.0 & $3(7.0)$ & $40(93.0)$ & 1.0 \\
\hline $15-17$ years & $78(18.8)$ & $336(81.2)$ & $1.8(0.69-4.74)$ & $1.7(0.71-4.67)$ & $55(13.7)$ & $347(86.3)$ & $2.1(0.63-7.07)$ \\
\hline 18 years + & $109(22.3)$ & $379(77.7)$ & $2.2(0.89-5.83)$ & $2.1(0.81-6.93)$ & $25(12.5)$ & $175(87.5)$ & $1.9(0.55-6.62)$ \\
\hline \multicolumn{8}{|l|}{ Location } \\
\hline Rural & $78(19.0)$ & $333(81.0)$ & 1.0 & 1.0 & 25 (11.6) & $191(88.4)$ & 1.0 \\
\hline Urban & $114(20.3)$ & $420(78.7)$ & $1.2(0.849-1.60)$ & $1.2(0.86-1.71)$ & $58(13.5)$ & $371(86.5)$ & $1.2(0.72-1.97)$ \\
\hline \multicolumn{8}{|l|}{ Live with parents } \\
\hline No & $49(17.3)$ & $225(82.1)$ & 1.0 & 1.0 & 29 (13.9) & $179(86.1)$ & 1.0 \\
\hline Yes & $143(21.3)$ & $529(78.7)$ & $1.2(0.87-1.78)$ & $1.3(0.89-1.89)$ & $54(12.4)$ & $383(87.6)$ & $1.1(0.71-1.87)$ \\
\hline \multicolumn{8}{|l|}{ Religiosity } \\
\hline Very Religious & $103(17.7)$ & 478 & 1.0 & 1.0 & $51(12.7)$ & $351(87.3)$ & 1.0 \\
\hline Somewhat religious & $81(23.7)$ & $261(76.3)$ & $1.4(1.04-2.00)^{*}$ & $1.4(1.03-2.01)^{*}$ & $30(13.5)$ & $192(86.5)$ & $1.1(0.66-1.74)$ \\
\hline Not religious & $8(20.3)$ & $14(63.6)$ & $2.7(1.08-6.49)^{*}$ & $2.9(1.17-7.11)^{*}$ & $2(12.9)$ & $17(89.5)$ & $0.8(0.18-3.61)$ \\
\hline \multicolumn{8}{|c|}{ Father/guardian's occupation } \\
\hline Professional & $82(21.2)$ & $305(78.8)$ & 1.0 & 1.0 & $6(17.1)$ & $29(82.9)$ & 1.0 \\
\hline Nonprofessional & $92(18.0)$ & $420(82.0)$ & $0.8(0.58-1.14)$ & $0.8(.55-1.09)$ & $38(12.0)$ & $278(88.0)$ & $0.7(0.26-1.69)$ \\
\hline Unclassified & $18(38.3)$ & $29(61.7)$ & $2.3(1.22-4.36)^{* *}$ & $2.5(1.30-4.76)^{* *}$ & $39(13.3)$ & $255(86.7)$ & $0.7(0.29-1.90)$ \\
\hline \multicolumn{8}{|l|}{ Mother's occupation } \\
\hline Professional & $39(22.3)$ & $136(77.7)$ & 1.0 & 1.0 & $15(11.3)$ & $118(88.7)$ & 1.0 \\
\hline Nonprofessional & $112(19.7)$ & $458(80.4)$ & $0.9(0.57-1.33)$ & $0.6(0.33-1.24)$ & $48(12.3)$ & $342(87.7)$ & $1.1(0.60-2.04)$ \\
\hline Unclassified & $41(20.4)$ & $160(79.6)$ & $0.9(0.54-1.53)$ & $0.7(0.34-1.35)$ & $20(16.4)$ & $102(83.6)$ & $1.5(0.75-3.17)$ \\
\hline \multicolumn{8}{|l|}{ Perceived SES } \\
\hline Very rich & $14(27.5)$ & $37(72.4)$ & 1.0 & 1.0 & $5(11.90)$ & $37(88.1)$ & 1.0 \\
\hline Somewhat rich & $106(20.0)$ & $424(80.0)$ & $0.6(0.34-1.27)$ & $0.6(0.33-1.24)$ & 47 (11.6) & $360(88.4)$ & $1.0(0.36-2.58)$ \\
\hline Poor & $71(20.1)$ & $283(79.9)$ & $0.6(0.34-1.29)$ & $0.7(0.34-1.35)$ & $30(16.0)$ & $157(84.0)$ & $1.4(0.51-3.89)$ \\
\hline
\end{tabular}

SES = socioeconomic status.

Bivariate and multivariate logistic regressions, respectively, indicate that family religiosity significantly predicted consumption of spirits among male students. Specifically, the findings show that coming from a not religious family is significantly associated with and predicted consumption of spirits among males. Moreover, males from highly religious families were less likely to consume spirits than those from less religious families. These findings are not surprising, as several similar results show that family religiosity is protective of alcohol consumption. For instance, Stafström and Agardh [8] found that family religiosity significantly predicted alcohol consumption among students. Furthermore, in their study to determine religion and religiosity as predictors of alcohol use among adults at a fishing site in Uganda, Tumwesigye et al. [28] found that people reporting low religiosity were five times more likely to have consumed alcohol. Other studies elsewhere show that strong religious attachment among adolescents and their families predicts less alcohol consumption among the adolescents $[29,30]$.

As the saying "charity begins at home" goes, religion in a family is still a big protective factor against alcohol consumption among adolescents in Uganda, especially among girls. Family religiosity in this case serves as a catalyst in helping adolescents internalize the values of their families. Adolescents' internalization of the values of their families may result in developing strategies to avoid alcohol consumption [31]. Similarly, Sinha et al. [32] assert that the youth were less likely to consume alcohol when the family commitment to the church and centrality of religion was high. Certainly, strong family religious beliefs build a cohesive family with values that do not permit alcohol consumption. A cohesive family would essentially encourage its children to adhere to societal values. For such a reason, cohesive family relationships may play a significant role as protective factors against youth drinking [19].

The present study found significant association between consumption of spirits among male students and fathers' occupation. Male students whose fathers' occupations were unclassified were more likely than those whose fathers were in professional occupations or nonprofessional occupations to consume spirits. It is not clear why unemployed category were particularly significant, but the findings appear to imply that unemployed were more engaging and poorly rewarding than other occupations. The consequence could have been fathers in such occupations having little or no time to interact with their sons, as less parental-child interaction is a risk factor for alcohol consumption $[2,3,18,33,34]$. Alternatively, possible low income among unemployed category could mean that their families created a risky environment for alcohol consumption [18]; especially 
among male adolescents. It was previously asserted that males from lower occupational backgrounds were more likely to consume spirits than their colleagues from higher occupational backgrounds and more often consumed larger amounts of alcohol $[3,16]$. Besides, parents play a vital role in the prevention of consumption of spirits among their children [35]. Despite the limitations of the study, the findings reported by this study are based on a self-report survey conducted among secondary school students. Like any other study based on self-reported data, the results engendered in our study are subject to under reporting on alcohol consumption.

\section{Conclusions}

This study investigated the prevalence and family factors associated with consumption of sprits across gender. The results show that the prevalence of consumption of spirits was higher among males. This suggests that preventive measures could be centred on male students. As indicated in the findings, early prevention of consumption of spirits could be focused on male students and on family religiosity. In addition, school administrators and authorities could consider these factors during routine school inspections, as inspections are one of the common ways to guard discipline among students in Uganda. Further research can be conducted to include educators from public and private secondary schools to compare the consumption of spirits among students across different institutions in Uganda and beyond.

\section{Data Availability}

The data used to support the findings of this study are available from the corresponding author upon request.

\section{Ethical Approval}

The study was approved by the Mbarara University Research Ethics Committee. Students' assented to participate in study while head teachers consented on behalf of parents and guardians, that is, for students under the age of 18 .

\section{Conflicts of Interest}

The authors declare no conflicts of interest regarding the publication of this work.

\section{Acknowledgments}

The authors convey appreciation to all participants for giving invaluable responses used in this study.

\section{References}

[1] A. Loke and Y.-W. Mak, "Family process and peer influences on substance use by adolescents," International Journal of Environmental Research and Public Health, vol. 10, no. 9, pp. 3868-3885, 2013.

[2] B. J. McMorris, R. F. Catalano, M. J. Kim, J. W. Toumbourou, and S. A. Hemphill, "Influence of family factors and supervised alcohol use on adolescent alcohol use and harms: similarities between youth in different alcohol policy contexts," Journal of Studies on Alcohol and Drugs, vol. 72, no. 3, pp. 418-428, 2011.

[3] M. Droomers, C. T. M. Schrijvers, S. Casswell, and J. P. Mackenbach, "Occupational level of the father and alcohol consumption during adolescence; patterns and predictors," Journal of Epidemiology \& Community Health, vol. 57, no. 9, pp. 704-710, 2003.

[4] Uganda Youth Development Link, State of Alcohol Abuse in Uganda, A UYDEL Publication, Kampala, Uganda, 2008.

[5] W. Naamara and W. W. Muhwezi, "Factors associated with alcohol dependence among adult male clients in butabika hospital, Uganda," Journal of Social Work Practice in the Addictions, vol. 14, no. 3, pp. 322-326, 2014.

[6] C. Abbo, E. Okello, W. Muhwezi, G. Akello, E. Ovuga, and M. Makinodan, "Alcohol, substance use and psychosocial competence of adolescents in selected secondary schools in Uganda: a cross sectional survey," International Neuropsychiatric Disease Journal, vol. 7, no. 2, pp. 1-14, 2016.

[7] J. John-Langba, A. Ezeh, G. Guiella, A. Kumi-Kyereme, and S. Neema, "Alcohol, drug use, and sexual-risk behaviours among adolescents in four Sub-Saharan African countries," in Proceedings of the Population Association of America 2006 Annual Meeting Program, Los Angeles, California, April 2006.

[8] M. Stafström and A. Agardh, "Socio-economic determinants for alcohol consumption and heavy episodic drinking in a Ugandan student population," The International Journal of Alcohol and Drug Research, vol. 1, no. 1, pp. 57-67, 2012.

[9] G. C. K. Chan, J. Leung, C. Quinn et al., "Rural and urban differences in adolescent alcohol use, alcohol supply, and parental drinking," The Journal of Rural Health, vol. 32, no. 3 , pp. 280-286, 2016.

[10] A. J. Gale, J. D. Lenardson, D. Lambert, and D. Hartley, “Adolescent alcohol use: do risk and protective factors explain rural-urban differences?" 2012, http://www.ruralhealthresearch. org.

[11] P. J. Gruenewald, L. G. Remer, and E. A. LaScala, "Testing a social ecological model of alcohol use: the California 50-city study," Addiction, vol. 109, no. 5, pp. 736-745, 2014.

[12] T. Osman, C. Victor, A. Abdulmoneim et al., "Epidemiology of substance use among university students in Sudan," Journal of Addiction, vol. 2016, Article ID 2476164, 8 pages, 2016.

[13] Uganda Alcohol Policy Alliance, Underage Alcohol Consumption in Uganda, UAPA Publication, Kampala, Uganda, 2014.

[14] M. H. Swahn, J. B. Palmier, and R. Kasirye, "Alcohol exposures, alcohol marketing, and their associations with problem drinking and drunkenness among youth living in the slums of Kampala, Uganda," ISRN Public Health, vol. 2013, Article ID 948675, 9 pages, 2013.

[15] P. Dalgalarrondo, M. A. Soldera, H. R. Corrêa Filho, and C. A. M. Silva, "Religião e uso de drogas por adolescentes," Revista Brasileira de Psiquiatria, vol. 26, no. 2, pp. 82-90, 2004.

[16] O. E. Atherton, R. D. Conger, E. Ferrer, and R. W. Robins, "Risk and protective factors for early substance use initiation: a longitudinal study of Mexican-origin youth," Journal of Research on Adolescence, vol. 26, no. 4, pp. 864-879, 2015.

[17] L. M. Handren, C. D. Donaldson, and W. D. Crano, "Adolescent alcohol use: protective and predictive parent, peer, and self-related factors," Prevention Science, vol. 17, no. 7, pp. 862-871, 2016. 
[18] A. Miller and J. M. Cook, "The adolescent substance use risk continuum: a cultural, strengths-based approach to case conceptualization," The Professional Counselor, vol. 7, no. 1, pp. 1-14, 2017.

[19] H. Gough, S. Longman-Mills, W. D. L. Haye et al., "Family relations, peer influence, spirituality and drug use among students in one university in Kingston, Jamaica," Texto \& Contexto-Enfermagem, vol. 24, no. spe, pp. 184-189, 2015.

[20] J. C. Cumsille, Essential Behavior Analysis, Oxford University Press, Oxford, UK, 2002.

[21] S. N. Kabwama, S. Ndyanabangi, G. Mutungi, R. Wesonga, S. K. Bahendeka, and D. Guwatudde, "Alcohol use among adults in Uganda: findings from the countrywide non-communicable diseases risk factor cross-sectional survey," Global Health Action, vol. 9, no. 1, Article ID 31302, 2016.

[22] H. Landrine, S. Bardwell, and T. Dean, "Gender expectations for alcohol use: a study of the significance of the masculine role," Sex Roles, vol. 19, no. 11-12, pp. 703-712, 1988.

[23] I. S. Obot and R. Robin Room, Alcohol, Gender and Drinking Problems: Perspectives from Low and Middle Income Countries, World Health Organization, Geneva, Switzerland, 2005.

[24] C.-C. Hung, H.-Y. Chang, D.-L. Luh, C.-C. Wu, and L.-L. Yen, "Do parents play different roles in drinking behaviours of male and female adolescents? A longitudinal follow-up study," BMJ Open, vol. 5, no. 4, Article ID e007179, 2015.

[25] E. N. Kuntsche and H. Kuendig, "What is worse? A hierarchy of family-related risk factors predicting alcohol use in adolescence," Substance Use \& Misuse, vol. 41, no. 1, pp. 71-86, 2006.

[26] A. Derese, A. Seme, and C. Misganaw, "Assessment of substance use and risky sexual behavior among Haramaya University students, Ethiopia," Science Journal of Public Health, vol. 2, no. 2, pp. 102-110, 2014.

[27] V. Lorant, P. Nicaise, V. E. Soto, and W. d'Hoore, "Alcohol drinking among college students: college responsibility for personal troubles," BMC Public Health, vol. 13, no. 1, p. 615, 2013.

[28] N. M. Tumwesigye, L. Atuyambe, S. P. S. Kibira, F. WabwireMangen, F. Tushemerirwe, and G. J. Wagner, "Do religion and religiosity have anything to do with alcohol consumption patterns? Evidence from two fish landing sites on Lake Victoria Uganda," Substance Use \& Misuse, vol. 48, no. 12, pp. 1130-1137, 2013.

[29] S. E. Luczak, C. A. Prescott, C. Dalais, A. Raine, P. H. Venables, and S. A. Mednick, "Religious factors associated with alcohol involvement: results from the Mauritian joint child health project," Drug and Alcohol Dependence, vol. 135, no. 135, pp. 37-44, 2014.

[30] F. F. Marsiglia, S. L. Ayers, and S. Hoffman, "Religiosity and adolescent substance use in Central Mexico: exploring the influence of internal and external religiosity on cigarette and alcohol use," American Journal of Community Psychology, vol. 49, no. 1-2, pp. 87-97, 2012.

[31] E. H. Telzer, N. Gonzales, and A. J. Fuligni, "Family obligation values and family assistance behaviors: protective and risk factors for Mexican-American adolescents' substance use," Journal of Youth and Adolescence, vol. 43, no. 2, pp. 270-283, 2013.

[32] J. W. Sinha, R. A. Cnaan, and R. J. Gelles, "Adolescent risk behaviors and religion: findings from a national study," Journal of Adolescence, vol. 30, no. 2, pp. 231-249, 2007.

[33] A. Baltazar, D. C. McBride, C. J. VanderWall, and K. Conopio, Sex, Drugs and Alcohol: What Adventist College Students Say about the Role of Parents and Religion, Faculty Publications: Andrews University, Berrien Springs, MI, USA, 2016.

[34] M. Jahanshahloo, S. Mohammadkhani, H. Amiri, and A. Fakhari, "Personal, family, and social risk and protective factors of tendency towards substance use among students," Community Health, vol. 3, no. 2, pp. 127-137, 2016.

[35] M. Hoque and S. Ghuman, "Do parents still matter regarding adolescents' alcohol drinking? Experience from South Africa," International Journal of Environmental Research and Public Health, vol. 9, no. 1, pp. 110-122, 2012. 


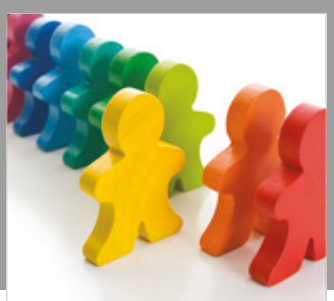

Autism

Research and Treatment
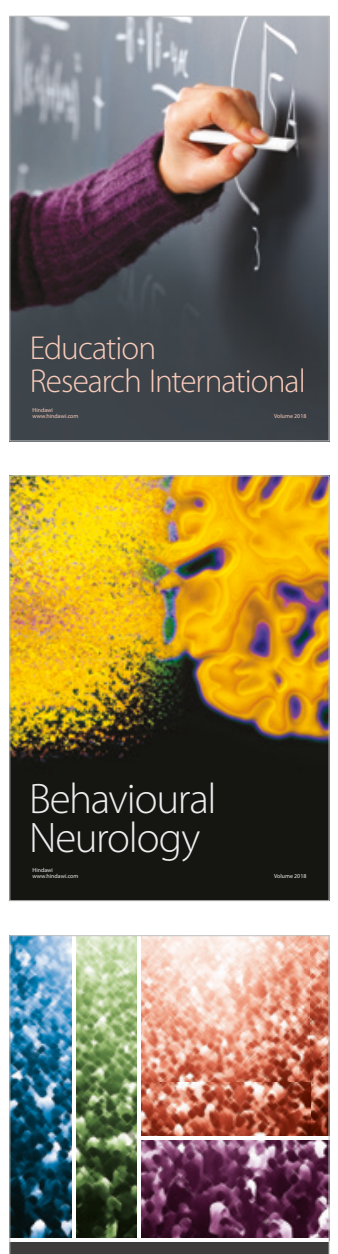

International Journal of

Population Research

$\underline{-m}$

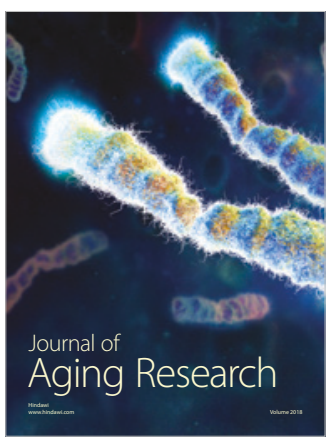

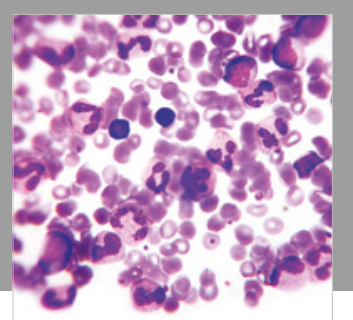

Pathology

Research International$$
=
$$

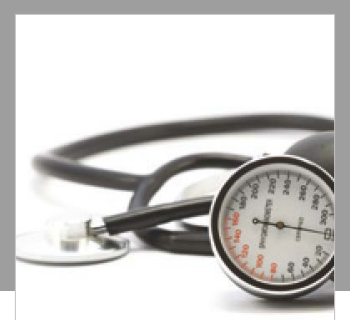

Nursing

Research and Practice

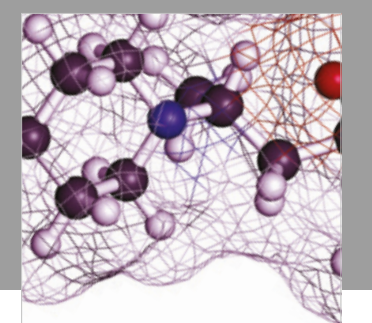

Pain

Research and Management

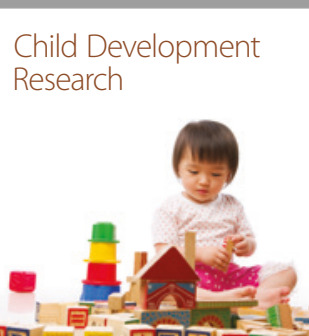

बाD

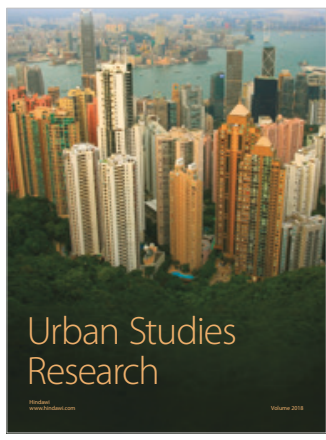

\section{Hindawi}

Submit your manuscripts at

www.hindawi.com
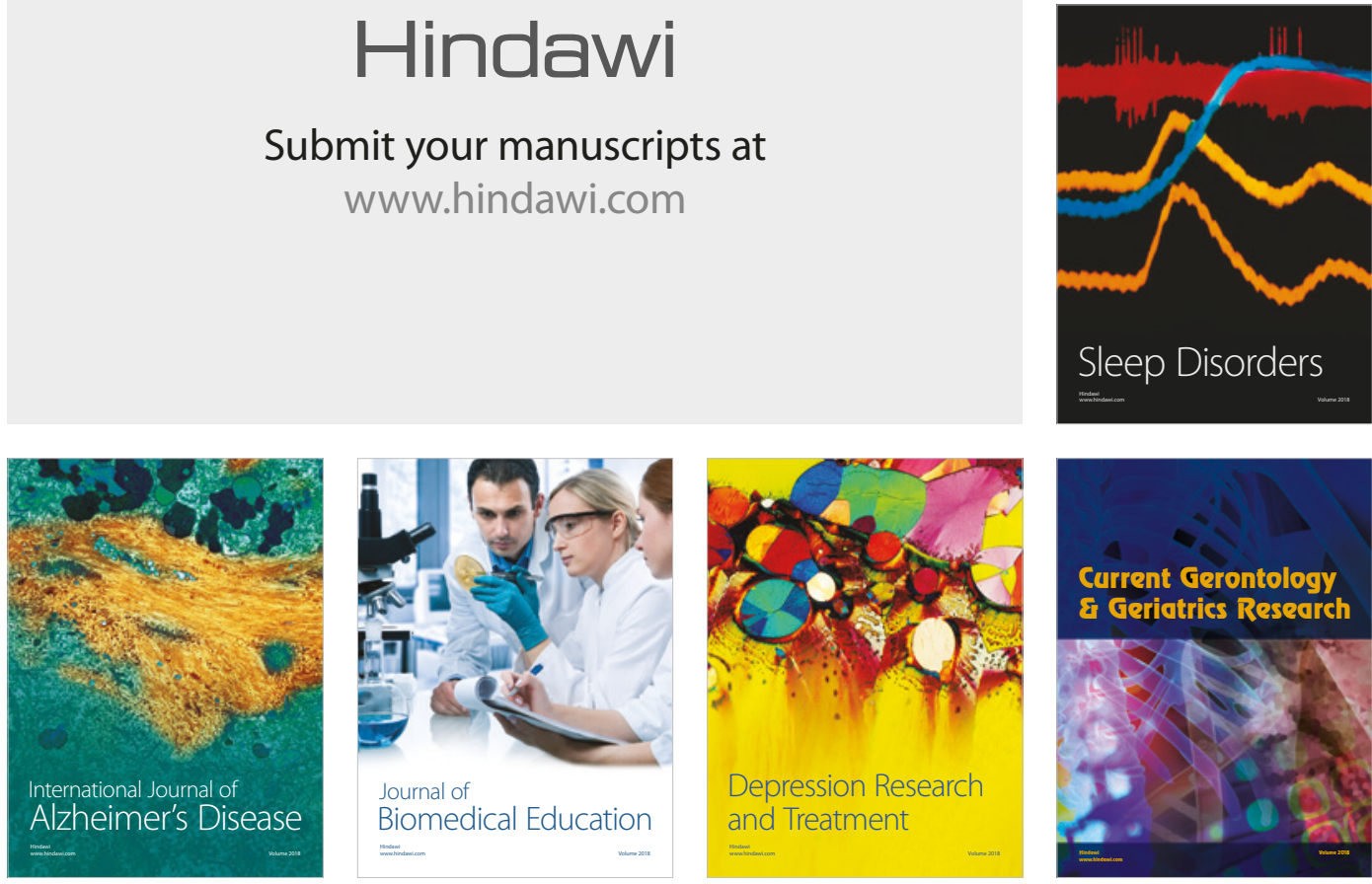

Journal of

Biomedical Education

$=$

smman

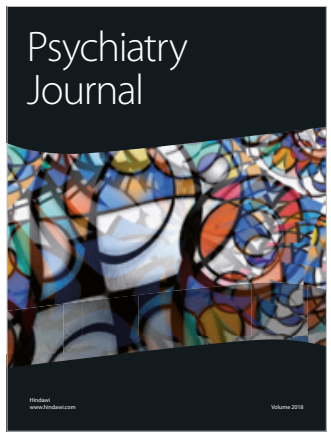

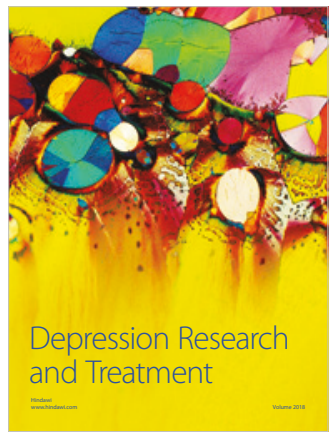
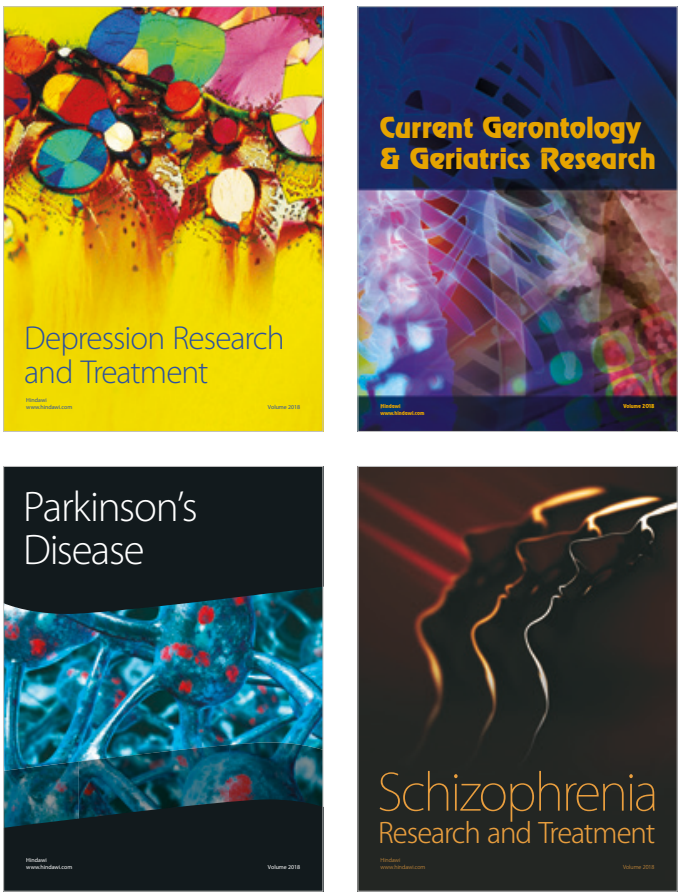